\title{
Exploring the Role of Fungal Endophytes in the Sudden Death Syndrome of the Invasive Shrub Chrysanthemoides monilifera subsp. rotundata in Australia
}

\author{
Louise Morin, ${ }^{1, \dagger}$ Andrew B. Bissett, ${ }^{2}$ and Rieks D. van Klinken ${ }^{3}$ \\ ${ }^{1}$ Health and Biosecurity, Commonwealth Scientific and Industrial Research Organisation, Canberra, Australian Capital Territory, 2601, \\ Australia \\ ${ }^{2}$ Oceans and Atmosphere, Commonwealth Scientific and Industrial Research Organisation, Hobart, Tasmania, 7001, Australia \\ ${ }^{3}$ Health and Biosecurity, Commonwealth Scientific and Industrial Research Organisation, EcoSciences Precinct, Brisbane, Queensland, \\ 4001, Australia
}

Accepted for publication 16 September 2021.

\section{ABSTRACT}

Pathogens that attack invasive plants can positively affect the integrity and functioning of ecosystems. Stem-tip dieback and extensive wilting followed by sudden death have been observed in Chrysanthemoides monilifera subsp. rotundata (bitou bush), one of Australia's worst invasive shrubs. Metabarcoding and culturing methods were used to investigate whether fungi are implicated in this syndrome. Metabarcoding results revealed significantly different endophytic fungal communities within healthy and diseased bitou bush, and colocated native plants. There was no difference in fungal communities between soil sampled in the root zone of healthy and diseased bitou bush at the same site. Two Diaporthe sp. operational taxonomic units (OTUs), dominant at sites with extensive wilting explained $30 \%$ of the similarity between diseased bitou bush across all sites. Two other OTUs, Austropleospora osteospermi and Coprinellus sp., explained 20 and $40 \%$ of the similarity between diseased plants, respectively, and were only dominant at sites with dead or stunted, partially defoliated but not wilted bitou bush. A Penicillium sp. OTU explained $90 \%$ of the similarity between healthy bitou bush plants. Various Diaporthe spp. dominated isolations from diseased bitou bush. Manipulative experiments confirmed Diaporthe spp. pathogenicity on bitou bush excised and in situ stems. In another experiment, Diaporthe masirevicii infected flowers and, from there, colonized stems endophytically; however, wilting and sudden death of bitou bush did not occur within the experimental timeframe. Our study provides circumstantial evidence that bitou bush sudden death syndrome is the result of a shift in the composition of its endophytic fungal community from mutualist to pathogenic species.

Keywords: endophytes, metagenomics, mycology, natural habitats, plant pathology, plants
Plant diseases play an important role in regulating plant populations and species diversity within natural ecosystems (Benítez et al. 2013; Bever et al. 2015; Burdon and Laine 2019; Dinoor and Eshed 1984).

${ }^{\dagger}$ Corresponding author: L. Morin; louise.morin@ csiro.au

Funding: The Australian Government as part of its previous National Weeds and Productivity Research Program administered by the Rural Industries Research and Development Corporation, now trading as AgriFutures Australia, project PRJ-007280.

*The $\boldsymbol{e}$-Xtra logo stands for "electronic extra" and indicates that supplementary materials are published online.

The author(s) declare no conflict of interest.

Copyright (c) 2022 The Author(s). This is an open access article distributed under the CC BY-NC-ND 4.0 International license.
Through their effects on plant physiology and population dynamics, pathogens can negatively affect ecosystem services such as carbon fixation and frequency and intensity of wildfires (Paseka et al. 2020). Endemic or introduced pathogens that attack invasive plant species, however, can positively affect the integrity and functioning of ecosystems (Flory and Clay 2013; Flory et al. 2018; Morin 2020). For example, by reducing the distribution and density of these harmful species, pathogens can indirectly benefit resident native species.

Discernible declines in the health of nonnative, woody invasive plants, sometimes referred to as dieback, have been reported in several species in Australia (Aghighi et al. 2014; Haque et al. 2019; Raghavendra et al. 2017; Wilson and Pitkethley 1992). These declines are typically associated with defoliation and death of plant parts and, eventually, of whole plants. Because the declines are not related to the age of the population or explained by external 
stressors such as prolonged drought or flooding, biotic factors are thought to be involved (Aghighi et al. 2016; Haque et al. 2019; Steinrucken et al. 2017a, b).

Culture-independent molecular methods such as metabarcoding (Nilsson et al. 2019) are particularly helpful to investigate declines in woody plant species that involve more than a single pathogen-plant interaction (Del Frari et al. 2019; Gómez et al. 2019; Morales-Cruz et al. 2018). These methods overcome difficulties associated with the isolation of multiple, interacting microorganisms, including some that cannot be isolated and grown in culture, are slowgrowing, or have specific nutrition requirements (Stefani et al. 2015). Steinrucken et al. (2016) identified different and diverse communities of archaeal, bacterial, and fungal operational taxonomic units (OTUs) in healthy and dieback-affected parkinsonia (Parkinsonia aculeata) plants, a leguminous invasive tree in northern Australia, using terminal restriction fragment length polymorphism. Their results supported the hypothesis that complex communities of microorganisms, including both pathogenic and nonpathogenic "protective" endophytes-based on the definition of endophytes by Hardoim et al. (2015)—could be involved in this decline. In contrast, no differences in fungal communities within stems or soils associated with healthy and dieback-affected parkinsonia, as well as for four other invasive plant species across northern Australia, were detected using metabarcoding (Raghavendra et al. 2017). These results highlighted that, even with advanced molecular tools, unraveling these complex declines remains a challenge.

In 2006, large, inexplicable dead patches in an infestation of bitou bush (Chrysanthemoides monilifera subsp. rotundata), an invasive plant originating from South Africa, were observed at Bongil Bongil National Park near Coffs Harbour, New South Wales (NSW), Australia. Within a few months, other dead bitou bush patches were identified in an area $20 \mathrm{~km}$ south of the park and, by 2008, patches of stunted and dead bitou bush were observed at several sites across a 60-km strip of coastline both north and south of Coffs Harbour. Extensive wilting of bitou bush and stem-tip dieback symptoms were typically observed prior to their sudden death and, thus, the phenomenon was referred to by land managers as bitou bush sudden death syndrome (SDS). Such wilting and death were not observed in other plant species growing near bitou bush. Patches of dead bitou bush were irregular in shape and not homogenous (i.e., sometimes bushes around the edge of the main dead patch were still alive and a few dead bushes were found 15 to $20 \mathrm{~m}$ further away). As far as we know, such unexplained sudden death of bitou bush has not been observed in the plant's native range.

Bitou bush is recognized as one of Australia's worst invasive plants of natural ecosystems, invading $80 \%$ of coastline habitats in NSW (Thomas and Leys 2002), and its management is a national priority (French et al. 2008; Winkler et al. 2008). Application of herbicides and manual removal are the main methods used to manage this woody plant (Vranjic et al. 2012), although considerable research to find effective biological control solutions has been ongoing for decades (Downey et al. 2007; French et al. 2019; Wood 2006).

Between 1992 and 1995, bitou bush infestations along the NSW coast were extensively surveyed to identify pathogens with potential for development as bioherbicides (Cother et al. 1996). Of the various fungi isolated from diseased specimens, Sclerotinia sclerotiorum, which was recovered from some sites, was the only one shown in glasshouse tests to be capable of killing young bitou bush (Cother 2000). This fungus, however, was not investigated further for development as a bioherbicide because of perceived risks to nontarget plants, due to its wide host range.

Cursory examinations of foliage samples collected from bitou bush at sites where SDS was observed in 2009-10 revealed the presence of several fungi, including Cercospora apii, Phomopsis spp. (= Diaporthe spp.), and Austropleospora osteospermi (Morin et al. 2010). The latter was the most frequently isolated fungus and a first record in Australia. S. sclerotiorum was not isolated from any of the specimens collected. Pathogenicity tests with A. osteospermi showed that it could defoliate bitou bush under optimal conditions, but it did not cause stem dieback or kill plants (Morin et al. 2010). Thus, a more in-depth investigation was necessary to elucidate the causes of bitou bush SDS.

In this article, we present results from a multipronged approach using metabarcoding, culturing methods, and manipulative experiments to investigate bitou bush SDS, based on the hypothesis that fungi are implicated in the phenomenon. Metabarcoding was used to compare endophytic fungal communities of diseased and healthy bitou bush from a range of sites. Some sites had active signs of onset of SDS (i.e., extensive wilting and dead plants) whereas, at other sites, only dead or stunted, partially defoliated but not wilting plants were observed; an advanced state in the progression of SDS. Fungal communities within native woody plants growing near diseased bitou bush and in soil collected in the root zone of diseased and healthy bitou bush were also characterized with metabarcoding. Isolations of fungi were made from internal stem tissue of diseased bitou bush at sites with active signs of SDS and from typical stemtip dieback symptoms associated with SDS. Once possible causal agents of SDS were identified, a series of manipulative experiments were performed to evaluate their pathogenicity. Results of our study illustrate the benefits of combining different approaches to explore the biotic causes of complex phenomena such as bitou bush SDS.

\section{MATERIALS AND METHODS}

Location and description of sites. Two sites located in the Coffs Harbour region, North Coast, NSW, where symptoms of onset of SDS (extensive wilting and stem-tip dieback) were present in bitou bush were sampled (sites 2 and 5) (Fig. 1; Supplementary Fig. S1; Supplementary Table S1). Samples were also taken from another three sites in this region (sites 1, 3, and 4) with signs of advanced SDS, where bitou bush were dead or stunted, partially defoliated, and with stem-tip dieback but not wilting at the time of sampling. Three other sites with healthy bitou bush on the NSW South Coast, more than $700 \mathrm{~km}$ away from the North Coast sites and where SDS symptoms had never been recorded, were sampled (sites 6, 7, and 8).

Plant sampling. At each of the five North Coast sites, an area comprising diseased bitou bush was selected and paired with a nearby area (25 to $120 \mathrm{~m}$ away) of healthy bitou bush (Supplementary Table S1). Five bitou bush with the most severe disease symptoms but still alive, and five of the healthiest bitou bush plants in each of the paired areas were sampled. Five healthy bitou bush were sampled at each of the three South Coast sites. Up to five of each of the dominant woody native plants (shrub, small tree, or vine) growing next to or near diseased bitou bush at each North Coast site were also sampled (Supplementary Table S1).

Five stem pieces ( 1 to $3 \mathrm{~cm}$ in diameter and 12 to $15 \mathrm{~cm}$ long) were cut with secateurs near the base of each plant, placed in a paper bag with a satchel of silica gel beads, and stored in an insulated cooler box. Blades of secateurs were immersed in 3\% sodium hypochlorite $(\mathrm{NaOCl})$ for 15 min after sampling each group of plants (diseased and healthy bitou bush and native plants) at each of the North Coast sites, and between sampling at each of the South Coast sites.

For each plant sample, stem pieces were surface sterilized in the evening of the collection day, or the following day, by immersing in $2 \% \mathrm{NaOCl}$ for $1 \mathrm{~min}$, rinsing twice in commercially available bottled drinking water or sterile distilled water for $2 \mathrm{~min}$, and 
blotting dry with paper towel. Pieces were then placed in a new paper bag with a new satchel of silica gel beads and stored at $4^{\circ} \mathrm{C}$ until being further processed in a laminar flow. There, the bark was removed from each piece using a sharp knife over more than half of the circumference and for 7 to $8 \mathrm{~cm}$ in length in the middle of the piece. A chisel was then used to remove thin slices (up to 30, each 1 to $3 \mathrm{~cm}$ long) from the wood (xylem) of the piece. The slices from all pieces contained in a sample were pooled together into a wax paper bag and stored at $4{ }^{\circ} \mathrm{C}$. The knife and chisel were immersed in $3 \% \mathrm{NaOCl}$ for 15 min between each sample.

Bitou bush plants with stem-tip dieback (Fig. 1D) were also sampled at site 4, where this symptom was the most prevalent and severe of all North Coast sites. A dozen stem pieces with tip dieback were cut from diseased plants that had not already been sampled, placed in a large paper bag with satchels of silica gel beads, and stored as above.
Soil sampling. Soil samples, including detritus but no visible root material, were collected beneath each bitou bush sampled at the North Coast sites (sites 1 to 5,5 to $10 \mathrm{~cm}$ in depth, total weight per sample approximately $150 \mathrm{~g}$ ). For each site, the five soil samples taken beneath each group of plants (diseased or healthy) were pooled into a single paper bag and placed in a cooler. In the evening of the collection day, soil from each bag was spread into a thin layer on sheets of aluminum paper and left to air dry at room temperature overnight. The samples were then stored at $4^{\circ} \mathrm{C}$ until further processing.

Metabarcoding of fungi in plant and soil samples. Nucleic acid extraction. For each North Coast site, five slices of internal stem tissue from each of the five diseased and five healthy bitou bush in each of the paired areas and from each of the native plants sampled were pooled to form a single sample for each category (diseased bitou bush, healthy bitou bush, and native plants). For
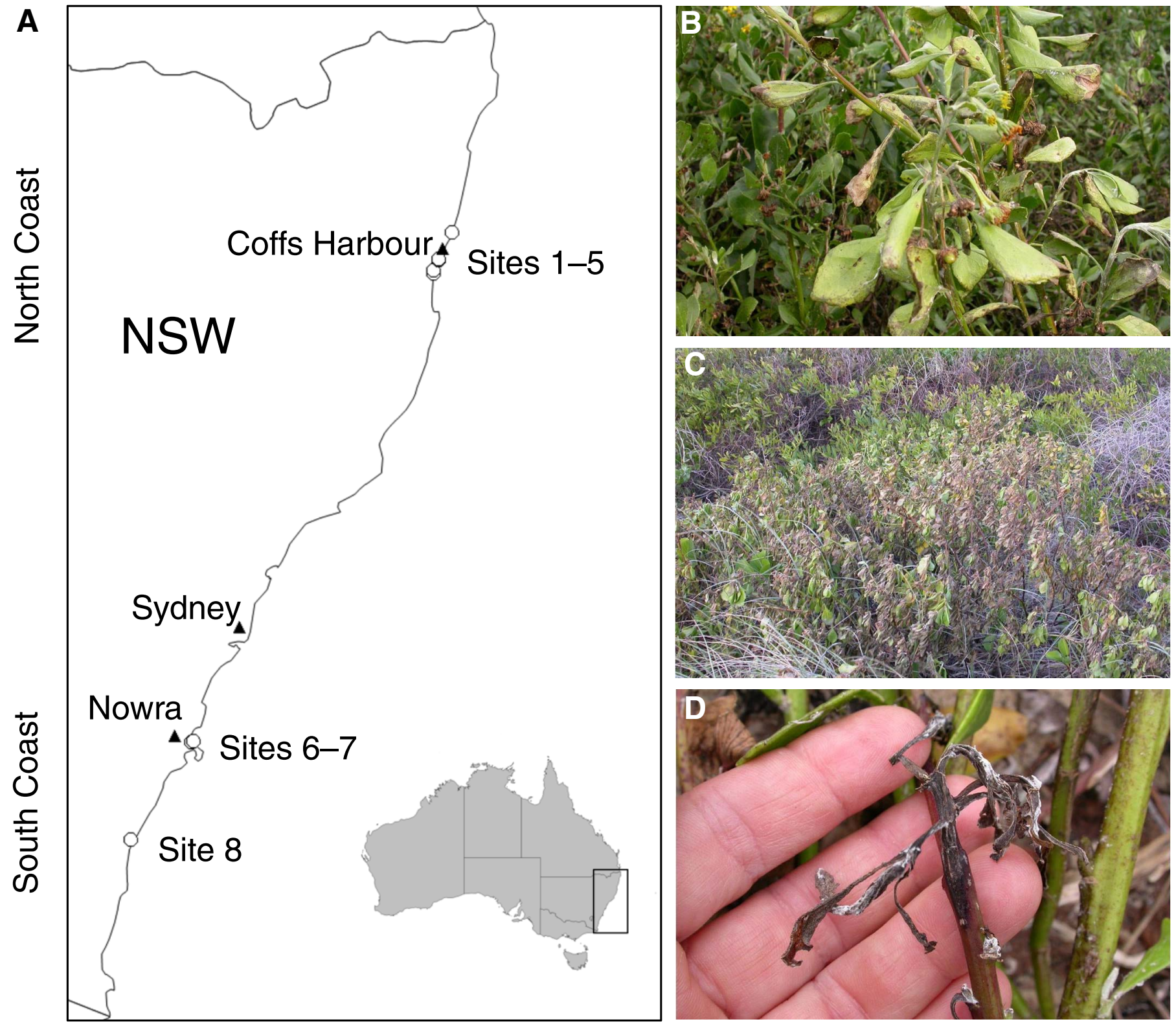

Fig. 1. A, Location of sites on the North Coast and South Coast of New South Wales sampled in the study (inset: location of sampled region in Australia). More details are shown in Supplementary Table S1. B and C, Bitou bush (Chrysanthemoides monilifera subsp. rotundata) exhibiting typical wilting symptoms observed at the onset of sudden death syndrome at sites 2 (B) and 5 (C). More photographs are shown in Supplementary Figure S1. D, Close-up of severe stem-tip dieback symptom on bitou bush at site 4 .

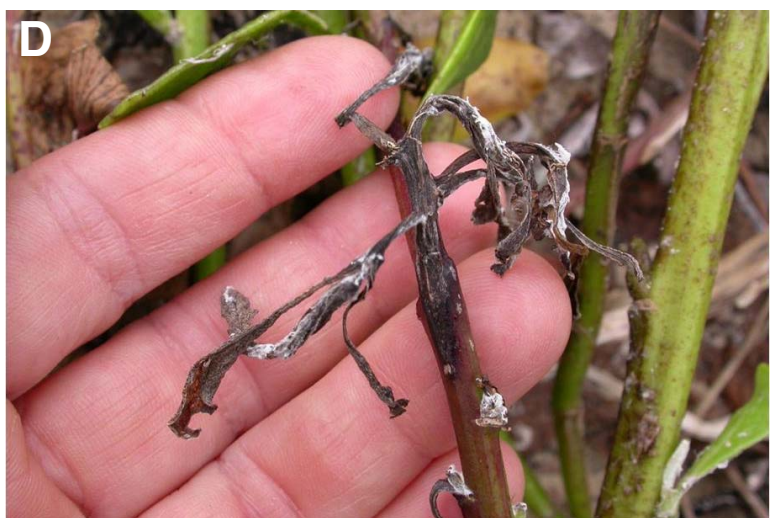


each South Coast site, a pooled sample of stem slices from healthy bitou bush was similarly prepared. All pooled samples were separately ground to a fine powder in liquid nitrogen and stored at $-80^{\circ} \mathrm{C}$ until DNA extraction. The DNA of two $0.25-\mathrm{g}$ subsamples of ground material from each pooled sample was extracted separately using the MO-BIO Power Soil DNA Isolation kit according to the manufacturer's instructions. Extractions were pooled and DNA was quantified spectrophotometrically (Nanodrop ND-1000; Thermo Scientific). Pooled soil samples (approximately $500 \mathrm{~g}$ each) were sent to the South Australian Research and Development Institute diagnostic laboratory for DNA extraction.

High-throughput internal transcribed spacer sequencing. DNA samples were sequenced at the Research and Testing Laboratory in Lubbock, TX, U.S.A. or MR DNA, Molecular Research LP in Shallowater, TX, U.S.A. The 454-pyrosequencing platform that was a well-established technology available at the time of this study in 2011 was utilized (454 GS FLX titanium technology; 454 Life Sciences). Samples were sequenced using fungal tag-encoded FLX amplicon pyrosequencing (Dowd et al. 2008). Fungal internal transcribed spacer (ITS) tag sequences were generated using primers ITS1F and ITS4R (Gardes and Bruns 1993) and established methods (Buée et al. 2009; Lim et al. 2010). Raw data in the form of standard flowgram format (sff) files were provided by the sequencing facilities for analysis.

Sequencing of reference isolates. To enrich the database used for analysis of metabarcoding sequences (see below), the ITS region of representative preserved cultures of nine fungi previously isolated from diseased symptoms on bitou bush along the NSW coast (Cother et al. 1996) was Sanger sequenced (Supplementary Material). These accessions were obtained from the NSW Plant Pathology Herbarium, Department of Primary Industries, Orange, NSW, Australia (Supplementary Table S2).

Analysis. The tag sequence data were analyzed using the OTU approach with the mothur software package (Schloss et al. 2009). This involved extraction of the sequences and flowgrams from the sff files, demultiplexing, and error checking via the Pyronoise algorithm (Edgar et al. 2011; Quince et al. 2009). Further quality screening of the sequence data included removing short reads ( $<150 \mathrm{bp}$ ), reads with long homopolymers ( $>8-\mathrm{bp}$ repeats), and truncating ITS reads $>500 \mathrm{bp}$ after removal of the forward primer sequence. Chimeras were identified with the UCHIME algorithm (Edgar et al. 2011) and removed. Sequences were preclustered at $1 \%$ sequence dissimilarity (Huse et al. 2010). Finally, the ITS1 region was obtained from the sequences using the Fungal ITS Extractor ITSx (Nilsson et al. 2009).

The USEARCH software package (Edgar 2010) was used to cluster ITS1 reads at $97 \%$ sequence similarity. These OTU sequences were then compared with sequences of a custom-made database comprising the UNITE fungal database (Kõljalg et al. 2005) and ITS sequences from the reference isolates (see above) and other fungi isolated as part of this study (see below), and assigned to their respective best matches. Sequence clusters were further refined by comparing them to the custom-made database using BlastN (Altschul et al. 1990), as implemented in the fungal ITS analysis software pipeline of Nilsson et al. (2009). Finally, OTUs were manually refined using consensus matches to assign singleton OTUs to existent clusters where the taxonomy led us to believe that utilizing the sequence similarity algorithm alone had oversplit the dataset. True singleton OTUs were removed from further analysis because they added no treatment interpretable information to our study. An OTU abundance-by-sample matrix was generated from the data with QIIME (Caporaso et al. 2010). Sequence data generated from this study have been deposited with the NCBI Sequence Read Archive under BioProject ID PRJNA744002.
An analysis of similarities (ANOSIM) was performed to identify OTU community differences between soil samples and between stem samples from the three groups of plants (diseased bitou bush, healthy bitou bush, and native plants), which were each pooled across sites. The nonmetric multidimensional scaling (nMDS) ordination method in the software Primer 6.1 (Clarke and Warwick 1994) was used to structure data along simple axes expressing overall OTU compositional similarity between groups of samples. Both ANOSIM and nMDS use the Bray-Curtis measure of similarity. The OTUs explaining community differences between groups of plant samples were identified with a similarity percentage (SIMPER) analysis. Phylogenetic analyses were then performed to demonstrate the evolutionary relationships between sequences of the key OTUs and relevant sequences from GenBank. Sequences were aligned and trees constructed using the ARB software (Ludwig et al. 2004). Complete ITS1 sequences for each group of sequences were aligned, initially using the ARB aligner, and refined manually. Neighbor-joining phylogenetic trees were constructed using PHYLIP 3.6 with the F84 nucleotide substitution model (Felsenstein 2005). To determine the support for each clade and assess the reliability of the branching pattern, bootstrap analysis was performed using 1,000 replications.

Isolation and identification of fungi from selected samples. Small pieces (approximately $0.5 \mathrm{~cm}^{2}$ ) cut from each slice of internal stem tissue from diseased bitou bush at North Coast sites 2 and 5 and pieces of stems severely affected by tip dieback at site 4 were surface sterilized and placed on agar plates (Supplementary Material). Plates were incubated at room temperature under 24-h fluorescent lights and, once colonies began to grow, pieces of hyphae from their margin were transferred onto fresh potato dextrose agar (PDA) and half-strength PDA amended with streptomycin sulfate at $200 \mu \mathrm{g} \mathrm{ml}^{-1}$ (1/2PDAS) plates kept under the same conditions. Plates were examined for fruiting bodies at weekly intervals over a 2-month period with a stereoscopic microscope. Clean cultures of the isolates were maintained as pieces of colonized $1 / 2$ PDAS immersed in sterile saline solution in vials stored at $4^{\circ} \mathrm{C}$.

Isolates were identified to at least the genus level using morphological characteristics. DNA was extracted from fresh cultures of all isolates recovered from diseased samples collected at sites 2 and 5, except for A. osteospermi isolates, which were easily identified with morphological characteristics. For site 4 samples, DNA was only extracted from Diaporthe sp. isolates, which were of the most interest based on metabarcoding results. The ITS region of all DNA samples was Sanger sequenced (Supplementary Material). Sequenced isolates were identified to the species level, where possible, by comparing with sequences in GenBank using BlastN.

Comparison of detection techniques. Results of isolations made from internal stem tissue of diseased bitou bush at sites 2 and 5 were compared with those obtained through metabarcoding of DNA extracted from material taken from the same samples. This comparison was performed to determine the efficiency of each technique in detecting fungi within bitou bush.

Pathogenicity of Diaporthe spp. Excised stems experiment. The pathogenicity of one to four isolates of each of the Diaporthe spp. recovered from diseased bitou bush was tested on excised stems of bitou bush using methods inspired from those of Hüberli et al. (2002) and Taylor et al. (2009). Pieces of the fleshy main stem (7 to $8 \mathrm{~mm}$ in diameter and 13 to $14 \mathrm{~cm}$ long) were cut from plants (Supplementary Material), their cut ends sealed with a piece of Parafilm (American National Can, Menasha, WI, U.S.A.), and all leaves removed. A surface-sterilized scalpel was used to cut back, in the middle of each stem piece, a small section (approximately $1 \mathrm{~cm}$ long and $5 \mathrm{~mm}$ wide) of the outer layers of the stem, leaving the xylem intact and creating a flap. 
A culture of each isolate was established on a 1/2PDA plate by inoculating it with a small piece of colonized agar from the stored culture. Plates were incubated at room temperature under $12 \mathrm{~h}$ of near-ultraviolet lights for each of 4 to 5 days. Discs $(5 \mathrm{~mm}$ in diameter) were cut from the actively growing margin of colonies, placed mycelium down on the xylem of the cut section of each excised stem, and covered back with the flap of stem outer layer tissue. Stem pieces were placed (inoculated wound facing upward) in plastic trays lined with moist paper towel inside plastic bags. Pieces with wounds only and others on which an uncolonized agar disc was placed under the flap of the wound were used as negative controls. Trays were placed in a controlled-environment room in the dark at 18 to $20^{\circ} \mathrm{C}$. A randomized complete block design with four blocks (i.e., trays; one inoculated stem piece per isolate in each tray) was used and the experiment was performed twice.

The length of the necrotic lesion that developed on each stem piece was measured at 6 days after inoculation (dai). Data from each trial were analyzed separately with one-way analysis of variance using untransformed data, after checking normality of the data, with the statistical package $\mathrm{R}$ (release 3.4.4) (R Core Team 2018). Treatments for which no lesion developed across all replicates were excluded from the analysis because of lack of variance. Differences between means were established with the Tukey multiple comparison procedure.

In situ stems experiment. The pathogenicity of one or two isolates of each of the Diaporthe spp. used in the above experiment was tested in situ on bitou bush. Wounded main stems on plants (Supplementary Material) were inoculated using a method similar to that of van Rensburg et al. (2006). A section (approximately $2 \mathrm{~cm}$ long and $1 \mathrm{~cm}$ wide) of the outer layers of the main stem on each plant was cut back with a surface-sterilized scalpel, leaving the xylem intact and creating a flap. The cut was made at $30 \mathrm{~cm}$ from the growing tip of the plant. Each plant was inoculated with a different Diaporthe sp. using the same methods outlined in the above experiment. The flap with the colonized agar disc was loosely wrapped with a thin strip of Parafilm. Plants with an uncolonized agar disc placed under the flap of the wound were used as negative controls. All plants were placed in humid chambers (plastic boxes, 40 by 30 by $29 \mathrm{~cm}$, containing water to a depth of $3 \mathrm{~cm}$ and placed in sealed, large transparent plastic bags) in a controlled-environment room (12-h photoperiod; fluorescent lights) at 18 to $20^{\circ} \mathrm{C}$ for $48 \mathrm{~h}$, then transferred to the bench in the room. The experiment was performed twice using a completely randomized design with four (trial 1) and three (trial 2) replicate plants per isolate and control. Plants were examined for disease symptoms at 3,10 , and 35 dai and length of stem lesions was measured. For each trial, lesion length data taken at 10 dai were analyzed separately as outlined above, using untransformed data.

Attempts to recover Diaporthe spp. from internal tissue of inoculated and control stems were made at 35 to 40 dai. An 8-cm-long section of the stem was cut upward from the upper edge of the wound or lesion and surface sterilized (Supplementary Material; method used with site 2 material). The stem section was then cut into 1-cm-long pieces with a scalpel surface sterilized between each cut. The pieces were placed on the surface of 1/2PDAS plates, which were incubated (as in the above experiment) and examined every second day for up to 2 weeks for colonies of Diaporthe spp.

In situ flowers experiment. Two isolates of one of the Diaporthe spp. tested in previous experiments, which sporulated profusely on artificial media, were used to determine their ability to cause stemtip dieback on bitou bush. A culture of each isolate was established on 1/2PDA plates, which were incubated as above but for longer (6 to 8 weeks). For each isolate, the content of a plate with a heavily sporulating culture was cut into 6 to 8 pieces, placed in a 50- to 60-ml solution of $0.05 \%$ Tween80 (Sigma-Aldrich, St. Louis, MO, U.S.A.) in distilled water contained in a beaker, and shaken vigorously to dislodge conidia. The solution was then filtered through Miracloth (Calbiochem, Merck KGaA, Darmstadt, Germany). The conidial density was determined using a hemocytometer and adjusted to $4 \times 10^{6}$ conidia $\mathrm{ml}^{-1}$ with distilled water-Tween 80 solution.

Bitou bush plants (Supplementary Material) with clusters of open flowers at the end of branches were selected for the experiment. A cluster of one to five flowers on the tip of one branch was sprayed to run-off with the conidial suspension of the isolates (one isolate per plant) using a hand-held sprayer. Flower clusters of control plants were sprayed with distilled water-Tween80 solution. Each sprayed flower cluster on a branch tip was placed with a piece of wet paper towel in a transparent plastic bag with a press-seal closure device. The bag was sealed and secured with tape around the branch, and plants were left in the glasshouse. Bags were removed after $48 \mathrm{~h}$. A completely randomized design with five or six replicate plants per isolate was used. The experiment was performed twice, with seven and three replicate control plants in trials 1 and 2, respectively. Plants, including inoculated flowers, were examined every 2 weeks, and disease symptoms were recorded. These observations were qualitative and not suitable for statistical analysis.

To determine whether the isolates had colonized stems endophytically following inoculations of flower clusters, a 16-cm-long section of the branch was cut just below the clusters at 10 weeks after inoculation. The section was cut into two equal-length subsections (keeping track of position relative to the cluster) and surface sterilized (Supplementary Material; method used with site 2 material). Each subsection was cut into $2-\mathrm{cm}$-long pieces using secateurs with surface-sterilized blades between each cut. Each piece was then cut in half longitudinally and placed on the surface of $1 / 2$ PDAS plates. Plates were incubated and examined for colonies of Diaporthe spp. as described above.

\section{RESULTS}

Metabarcoding of fungi in plant and soil samples. Analysis of plant samples. The proportional distribution of the different OTUs detected with metabarcoding in each of the samples from each site and the closest GenBank matches for the most abundant OTUs are presented in Supplementary Figures S2 to S4. The ANOSIM analysis revealed that the OTU community composition identified in diseased bitou bush at North Coast sites (1 to 5) was significantly different $(P=0.005 ; R=0.607)$ from that in healthy bitou bush from North and South Coast sites. The OTU community identified in native plants was also significantly different from those found in healthy $(P=0.001, R=0.684)$ and diseased $(P=0.008$, $R=0.768$ ) bitou bush. The nMDS analysis illustrated the relationship between OTU communities in these three group of samples (Fig. 2).

The SIMPER analysis identified the OTUs that explained up to $90 \%$ of the community similarity within each of the three groups of plants across sites (Fig. 3). Four OTUs (G51, G57, 549, and G62A) explained most of the similarity between communities within diseased bitou bush at North Coast sites. G51 and G57, both Diaporthe spp., were relatively highly abundant in wilted bitou bush from sites 2 or 5 (Supplementary Fig. S2), while the other two OTUs, 549 and G62A, were only found at sites 1, 3, and 4, where no wilting was observed at the time of sampling (Supplementary Fig. S3). In the phylogenetic analysis, G57 grouped with Diaporthe kongii within a well-supported clade (92\% bootstrap support [BS]) (Supplementary Fig. S5). In contrast, G51 grouped with two small clades, one comprising $D$. beilharziae and $D$. middletonii and the other D. infecunda, D. serafiniae, and D. sackstonii, into a larger 
clade but without significant support $(61 \% \mathrm{BS})$. The sequence of 549 corresponded to that of A. osteospermi (Morin et al. 2010). OTU G62A was identified as a Basidiomycetes fungus by nearest sequence match in GenBank and, in the phylogenetic analysis

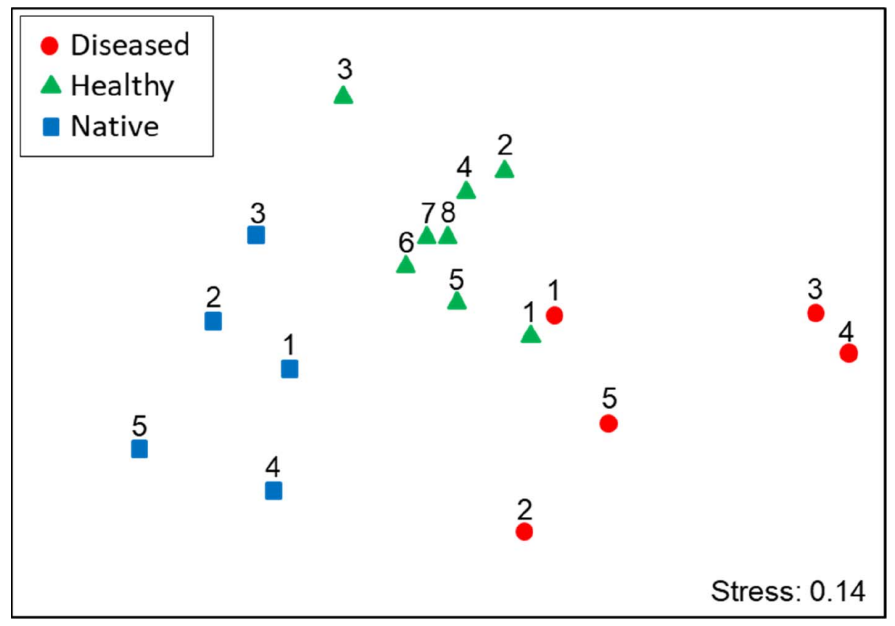

Fig. 2. Relationship among unique operational taxonomic units (OTUs) communities in diseased and healthy bitou bush (Chrysanthemoides monilifera subsp. rotundata), and native plants near diseased bitou bush at sites in New South Wales, as visualized by a nonmetric multidimensional scaling plot with a two-dimensional-stress level of 0.14. Sites 1 to $5=$ North Coast and sites 6 to $8=$ South Coast (healthy bitou bush only). performed, it grouped with several accessions in the Coprinellus genus within a well-supported clade (98\% BS) (Supplementary Fig. S6).

Interestingly, both Diaporthe sp. OTUs G51 and G57 were also detected in diseased and healthy bitou bush at site 1, while G51 was relatively abundant in healthy bitou bush at site 5 (Supplementary Figs. S2 and S3). Another Diaporthe sp. OTU, G50, which was not identified in the SIMPER analysis as a main contributor to the OTU community similarity between diseased bitou bush across sites, was also found in very high relative abundance in diseased bitou bush at site 2 (Supplementary Fig. S2). Although G50 was classified as a Diaporthe sp. by nearest sequence match, it did not group with any of the clades of the phylogenetic tree built with sequences of Diaporthe spp. in GenBank (Supplementary Fig. S5).

A single OTU, G14 - a Penicillium sp.-explained most of the community similarity between healthy bitou bush at North and South Coast sites. G14 was the most dominant OTU in healthy bitou bush at sites 2 and 5 on the North Coast (Supplementary Fig. S2) and the three South Coast sites (Supplementary Fig. S4). It was also relatively highly abundant in healthy bitou bush at site 4 , while it was one of the three major OTUs in diseased bitou bush at site 1 (Supplementary Fig. S3). The phylogenetic analysis grouped G14 in a clade that comprises Penicillium thomii, $P$. glabrum, $P$. adametzioides, $P$. spinulosum, and $P$. crustosum (Supplementary Fig. S7).

Several OTUs, including an Epicoccum sp. and a fungus belonging to the Dothideomycetes class, explained the similarity between communities within native plant samples (Fig. 3). None of the abundant OTUs identified in native plants were detected in any of the bitou bush samples (Supplementary Figs. S2 to S4). A single Diaporthe sp. OTU (162) was identified in the native plant sample

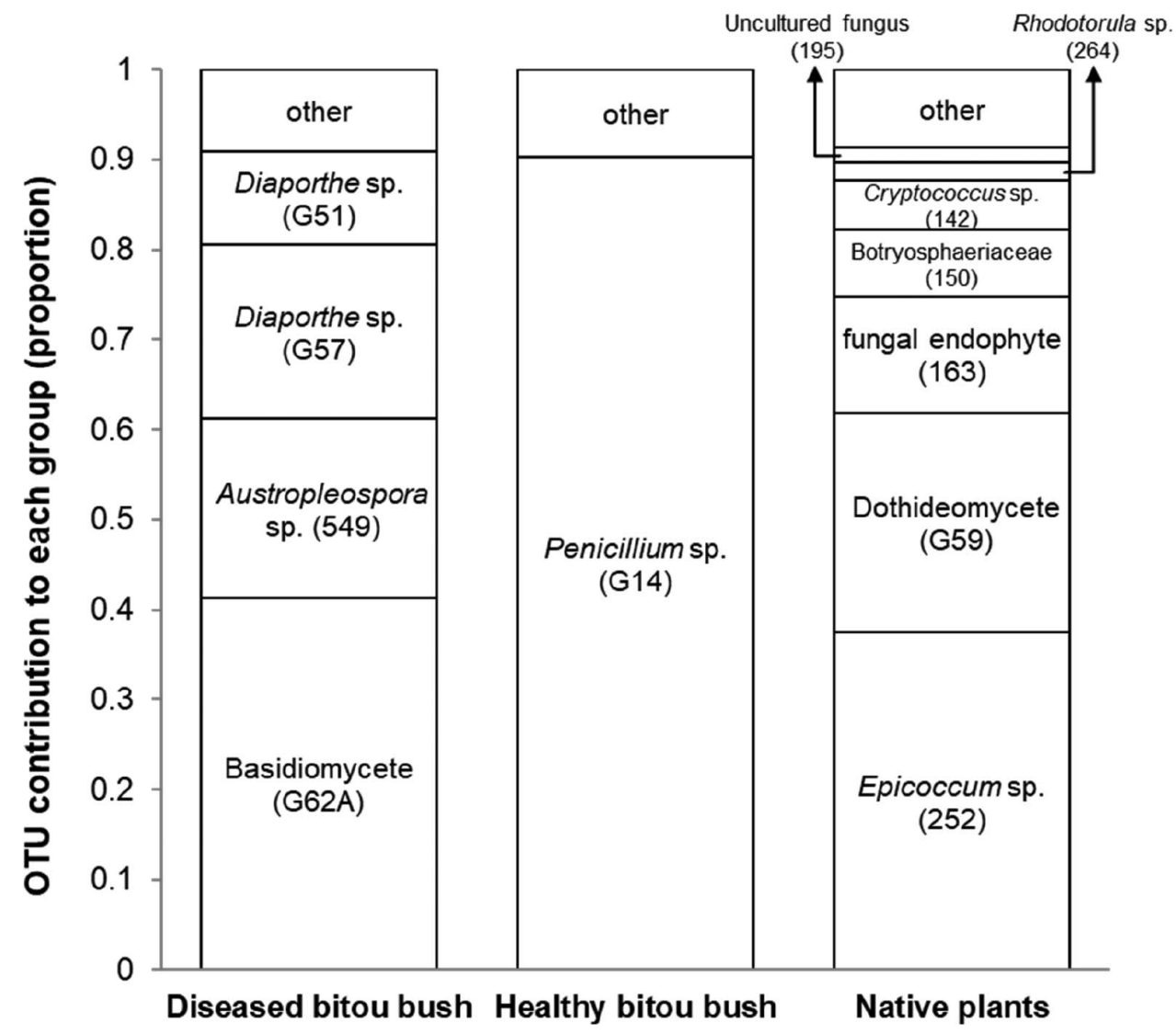

Fig. 3. Similarity percentage analysis of abundance of operational taxonomic units (OTUs) (with the name of their respective best sequence match indicated) that contributed up to $90 \%$ of the similarity within groups of plants sampled across sites in New South Wales. 
from site 5. This OTU is different from the Diaporthe sp. OTUs found in bitou bush. It grouped in the phylogenetic analysis with D. foeniculacea (synonym of D. neotheicola) and D. macintoshii in a clade without significant support $(61 \%$ BS) (Supplementary Fig. S5).

Analysis of soil samples. The ANOSIM analysis indicated there was no significant difference in the community of OTUs between soil samples collected beneath diseased and healthy bitou bush at each of the North Coast sites $(P=0.778)$. The nMDS analysis revealed that soil samples from diseased and healthy bitou bush at one site shared more OTUs with each other than with samples from other sites (Fig. 4). One of the dominant OTUs recovered from bitou bush, the Coprinellus sp. G62A, was detected at low relative abundance $(<9 \%)$ in all soil samples except the one taken beneath diseased bitou bush at site 3 . The Penicillium sp. OTU G14 was also detected, albeit at very low levels $(<0.1 \%)$, in soil samples across most plants and sites. Diaporthe sp. OTUs G50, G51, and G57 and A. osteospermi OTU 549 were only found in one to three soil samples, respectively, also at very low levels $(<0.2 \%)$.

Isolation and identification of fungi from selected samples. Two Diaporthe spp.-D. kongii and a novel species, D. masirevicii, described by Thompson et al. (2015)—were isolated from internal stem tissue of some diseased bitou bush at both sites 2 and 5, where wilting symptoms were observed (Table 1; Supplementary Table S3). Two other fungi, a Fusarium sp. and A. osteospermi, were also isolated from one and four diseased plants, respectively, at site 5 .

Fungi across a range of genera, including Alternaria, Botryosphaearia, Cercospora, Colletotrichum, Fusarium, Pestalotia, Stemphyllum, and Diaporthe, were isolated from samples with severe stem-tip dieback symptoms on bitou bush at site 4 (Supplementary Table S3). The Diaporthe spp. consisted of D. kongii and D. masirevicii, which were also isolated from internal stem tissue at other sites (Table 1; Supplementary Table S3). Another novel species, $D$. middletonii, described by Thompson et al. (2015), which was not recovered from any other samples collected during the study, was also isolated (Supplementary Table S3).

Comparison of detection techniques. OTUs with sequences that perfectly matched those of two of the four fungi isolated from diseased bitou bush at sites 2 and 5,D. kongii and A. osteospermi,

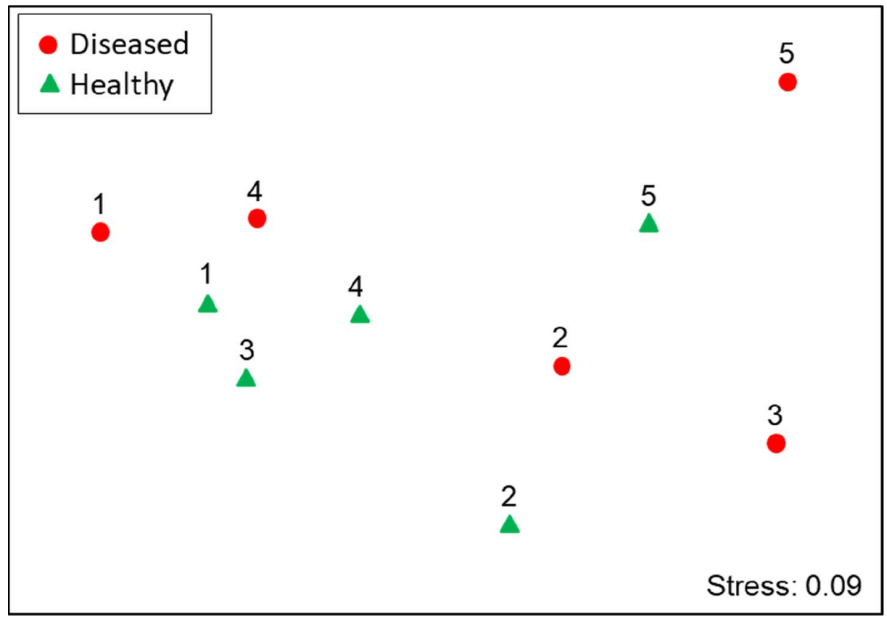

Fig. 4. Relationship among unique operational taxonomic units (OTUs) communities in diseased soil collected beneath diseased and healthy bitou bush (Chrysanthemoides monilifera subsp. rotundata) at each of the New South Wales North Coast sites (numbers 1 to 5), as visualized by a nonmetric multidimensional scaling plot with a two-dimensional-stress level of 0.09 were detected by metabarcoding (Table 1). Very high numbers of D. kongii-matching sequences were detected in the sample from each site. Although high numbers of sequences of three Diaporthe sp. OTUs (G50, G51, and G202) were detected in samples from one or both sites, including more than 6,000 sequences of OTU G50 in the site 2 sample, these did not perfectly match with those of D. masirevici isolates. Overall, metabarcoding detected two to five times more OTUs across the samples than the number of fungi isolated.

Pathogenicity of Diaporthe spp. Excised stems experiment. Isolates of all three Diaporthe spp. recovered from diseased bitou bush at North Coast sites-D. kongii, D. masirevicii, and D. middletonii-caused necrotic lesions of various length on excised stem pieces in one or both trials (Fig. 5; Supplementary Fig. S8). None of the control pieces developed any lesions in or around the wound where an uncolonized agar disc was placed. There was a statistically significant difference between isolates that caused lesions in both trials (trial 1: $F_{6,18}=7.84, P<0.001$; and trial 2: $F_{4,12}=4.7$, $P=0.016)$, with no significant block effect $(P>0.1)$. One isolate of each of D. kongii (57324) and D. middletonii (57329) only caused lesions in one trial. The average length of lesions was longer in trial 1 than in trial 2 for the other isolate of D. kongii (57332) and three isolates of $D$. masirevicii $(57327,57337$, and 57338) but it was the opposite for $D$. masirevicii 57330. Across both trials, $D$. masirevicii 57327 caused the longest lesions, although these were not significantly different from those caused by some of the other isolates tested (Fig. 5).

In situ stems experiment. All Diaporthe sp. isolates tested caused necrotic lesions on the inoculated main stem of bitou bush in both trials (Fig. 6; Supplementary Fig. S9A). The lesions did not expand further after their length was measured at 10 dai. No lesion developed on stems of control plants into which an uncolonized agar disc was placed (Supplementary Fig. S9B). A statistically significant difference in lesion length between isolates was found in each trial (trial 1: $F_{3,12}=7.22, P=0.005$; and trial 2: $F_{3,8}=21.45$, $P<0.001$ ). Across both trials, D. kongii 57332 and D. masirevicii 57327 caused significantly longer lesions that those produced by $D$. masirevicii 57338 (Fig. 6). Diaporthe sp. colonies were only recovered from internal tissue beyond the lesion edge in plants inoculated with the two isolates that caused the longest lesions (Table 2). Colonies were recovered in most plants up to $1 \mathrm{~cm}$ beyond the lesion edge although, in two plants inoculated with D. masirevicii 57327, colonies were recovered up to 6 and $8 \mathrm{~cm}$ from the lesions. In all cases, the morphology of the colonies matched that of the fungus used for inoculation.

In situ flowers experiment. In both trials, necrosis was first observed on the involucres of some of the flowers 5 days after clusters were sprayed with a conidial suspension of the two D. masirevicii isolates tested. By 13 dai, the inoculated flowers had dried up and necrotic lesions had developed on most peduncles but not on the tip of branches (Supplementary Fig. S9C and D). No necrosis was observed on any parts of the flowers and stems in control plants (Supplementary Fig. S9E). By the end of the trials at 10 weeks after inoculation, there was no visible difference across all plants, with flower clusters shriveled in both inoculated and control plants and no fruit produced. Diaporthe sp. colonies with a morphology matching that of D. masirevicii were recovered in internal stem tissue up to $16 \mathrm{~cm}$ from the base of the flower cluster inoculated with either isolate in the first trial (Table 2). Colonies were recovered from fewer stem pieces in the second trial but, nonetheless, the fungus was recorded up to $14 \mathrm{~cm}$ from the flower cluster in one of the plants inoculated with isolate 57327. Diaporthe sp. colonies were not recovered from stem pieces in any of control plants. 


\section{DISCUSSION}

All plant species are associated with communities of fungal endophytes that typically comprise a range of functional groups (Brader et al. 2017; Hardoim et al. 2015; Porras-Alfaro and Bayman 2011). Our study revealed major differences between communities of fungal endophytes in diseased and healthy bitou bush but, overall, no difference in fungal communities present in soil sampled from the root zone of these plants at the same site. Totally different endophytic fungal communities were found in native plants growing near diseased bitou bush. The endophytic communities in diseased bitou bush varied depending on whether extensive wilting, an active sign of SDS, was present. Fungi in the Diaporthe genus were the dominant OTUs and species detected by metabarcoding and isolations in these wilted plants. Manipulative experiments with the different Diaporthe spp. isolated demonstrated their pathogenicity and ability to colonize stems endophytically, suggesting that they may play a role in bitou bush SDS.

The totally different communities of fungal endophytes in native plants compared with those in bitou bush were not surprising considering that host plant species are known to greatly influence the endophytic fungal community structure (Lau et al. 2013; Yao et al. 2019). The earliest infestation of bitou bush in Australia is suspected to be the result of seed introduced from South Africa via dry ship ballast in the early 1900s (Winkler et al. 2008). Although these seeds would have likely been colonized by fungal endophytes, it is most probable that bitou bush would have acquired other endophytes over time as the plant became widely used in the 1940s to 1960s for revegetation of coastal sand dunes after mining, and increasingly invasive (Winkler et al. 2008). However, our results indicated that colocated native plant species did not share fungal endophytes with diseased bitou bush and, thus, were not the source of putative pathogenic species causing SDS in bitou bush.

The similar fungal communities found in soil collected beneath diseased and healthy bitou bush at each site indicated that SDS is not caused by a soilborne fungus such as S. sclerotiorum, previously isolated from bitou bush in NSW (Cother 2000; Cother et al. 1996). Several of the OTUs identified in bitou bush stems were detected at low levels in the soil samples. Raghavendra et al. (2017) reported similar results in other systems and suggested that this is due to the presence in the soil of dead but not yet decomposed aboveground plant tissue containing fungal endophytes. Indeed, there is increasing evidence that foliar endophytes contribute to litter decomposition in soil (Wolfe and Ballhorn 2020). We cannot rule out that pathogenic soilborne oomycetes such as Phytophthora spp. causing root rot (Hansen et al. 2012) are not implicated in bitou bush SDS because metabarcoding only targeted fungi in our study. However, there was no evidence of root rot, and the

TABLE 1

Comparison of methods used to detect fungi within diseased bitou bush (Chrysanthemoides monilifera subsp. rotundata) plants ${ }^{a}$

\begin{tabular}{|c|c|c|c|c|c|c|}
\hline \multirow[b]{3}{*}{ Fungus isolated ${ }^{b}$} & \multicolumn{6}{|c|}{ Metabarcoding } \\
\hline & \multicolumn{2}{|c|}{ Plant ID ${ }^{\mathrm{C}}$} & \multirow[b]{2}{*}{ OTU detected } & \multirow[b]{2}{*}{ Sequence match ${ }^{d}$} & \multicolumn{2}{|c|}{ Sequences detected $(n)^{\mathrm{e}}$} \\
\hline & Site 2 & Site 5 & & & Site 2 & Site 5 \\
\hline \multirow{2}{*}{ Austropleospora osteospermi ${ }^{f}$} & $\ldots$ & $\ldots$ & G29A & Austropleospora sp. & - & 5 \\
\hline & $\cdots$ & $\ldots$ & 245 & Austropleospora sp. & - & 20 \\
\hline Diaporthe kongii & C, D & $\mathrm{D}, \mathrm{E}$ & G57 & Diaporthe sp. & 368 & 1,018 \\
\hline \multirow[t]{4}{*}{ D. masirevicii ${ }^{9}$} & A, C & $A, B$ & G50 & Diaporthe sp. & 6,152 & - \\
\hline & $\ldots$ & $\ldots$ & G51 & Diaporthe sp. & 176 & 456 \\
\hline & $\ldots$ & $\ldots$ & G202 & Diaporthe sp. & 198 & - \\
\hline & $\ldots$ & $\ldots$ & G68 & Debaryomyces sp. & - & 1 \\
\hline \multirow{4}{*}{ Fusarium sp. $^{\mathrm{g}}$} & $\ldots$ & $\ldots$ & 304 & Not determined & - & 14 \\
\hline & $\ldots$ & $\ldots$ & 539 & Not determined & 5 & - \\
\hline & $\ldots$ & $\ldots$ & 920 & Not determined & 1 & - \\
\hline & $\ldots$ & $\ldots$ & 1030 & Not determined & 1 & - \\
\hline Fungi/OTUs $(n)^{\mathrm{h}}$ & 2 & 4 & $\ldots$ & $\ldots$ & 10 & 9 \\
\hline \multicolumn{7}{|c|}{$\begin{array}{l}\text { a Fungi isolated from plants (labeled A to E) sampled at each of sites } 2 \text { and } 5 \text { on the North Coast of New South Wales compared with operational } \\
\text { taxonomic units (OTUs), including number of internal transcribed spacer (ITS) sequences, detected by metabarcoding in the pooled plant samples from } \\
\text { these two sites. The alignment of an isolated fungus with an OTU indicates a perfect match between their respective sequences. Symbols: - indicates } \\
\text { not isolated or detected in that sample, and ... indicates that there was no match between the isolated fungus and any of the OTUs, and vice versa. } \\
\text { b Accession numbers of the fungal isolates lodged with the Plant Pathology Herbarium (HERB-BRIP) of the Queensland Department of } \\
\text { Agriculture and Fisheries, Brisbane, Australia, and for ITS sequences lodged in GenBank, are provided in Supplementary Table S3. } \\
\text { c ID of plants from which fungus was isolated. } \\
\text { d Name of best GenBank sequence match. } \\
\text { e Number of sequences detected. Graphs of proportional distribution of major OTUs are provided in Supplementary Figure S2. } \\
\text { f Sequence from isolate BRIP } 51624 \text { of this fungus lodged as part of another study (Supplementary Table S2) (Morin et al. 2010) was used for this comparison. } \\
\text { g Sequence of isolated fungus was not detected by metabarcoding. } \\
\text { h Total number of fungi isolated/OTUs detected. }\end{array}$} \\
\hline
\end{tabular}




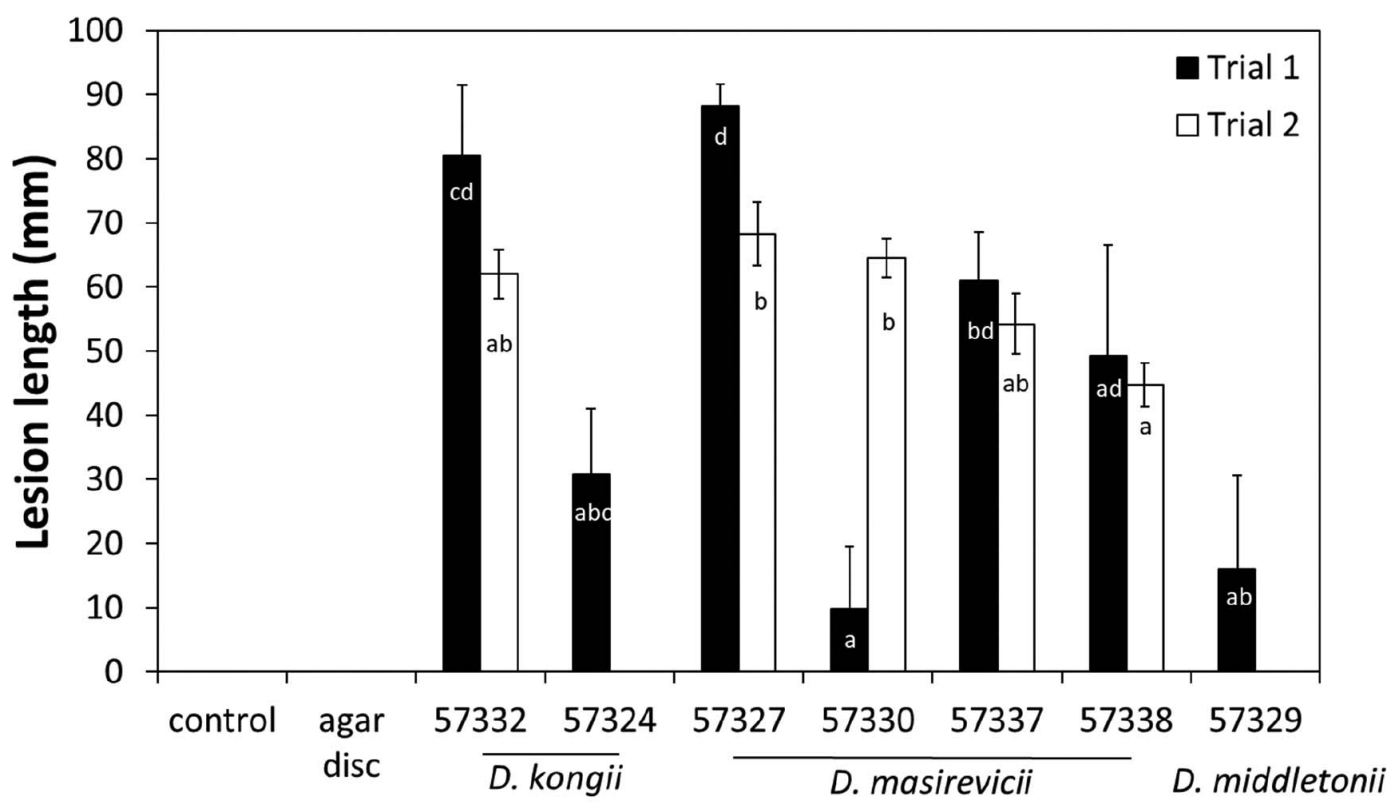

\section{Isolate}

Fig. 5. Length (mean \pm standard error) of necrotic lesions that developed on excised stem pieces of bitou bush (Chrysanthemoides monilifera subsp. rotundata) at 6 days after inoculation by placing an agar disc colonized by a Diaporthe sp. isolate (identified with BRIP accession number) into an artificial wound on each piece. Stem pieces with wounds only (control) and pieces with an uncolonized agar disc placed in the wound (agar disc) were used as negative controls. Treatments for which no lesion developed across all replicates were excluded from the analyses because of lack of variance. Treatments associated with the same letter within a trial have means that are not significantly different $(P>0.05)$ according to the Tukey multiple comparison procedure.

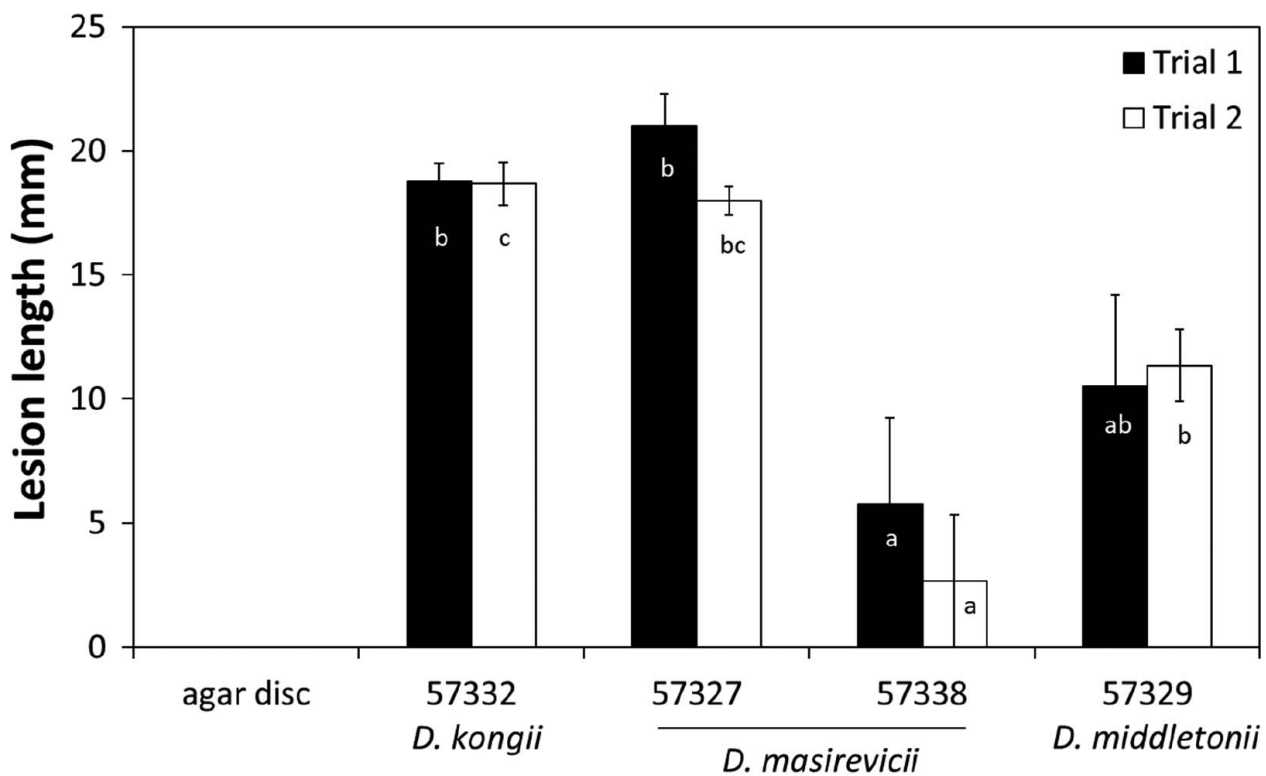

Isolate

Fig. 6. Length (mean \pm standard error) of necrotic lesions that developed on in situ stems of bitou bush (Chrysanthemoides monilifera subsp. rotundata) at 10 days after inoculation by placing an agar disc colonized by a Diaporthe sp. isolate (identified with BRIP accession number) into an artificial wound on the main stem of each plant. Stems with an uncolonized agar disc placed in the wound were used as negative controls. The agar-disc-only treatment for which no lesion developed across all replicates in each trial was excluded from the analyses because of lack of variance. Treatments associated with the same letter within a trial have means that are not significantly different $(P>0.05)$ according to the Tukey multiple comparison procedure. 
scattered distribution of dead bushes outside main patches affected by SDS suggested that the causal agents could be airborne.

Multiple Diaporthe spp. are commonly found on the same host plant, causing a range of disease symptoms either on their own or in combination (Guarnaccia et al. 2018; Thompson et al. 2011). In our study, three Diaporthe sp. OTUs (G50, G51, and G57) dominated the endophytic fungal communities in diseased bitou bush across sites 2 and 5, where extensive wilting was observed. The phylogenetic analysis linked OTUs G51 and G57 to Diaporthe spp. isolated from live or dead stems of crops, including sunflower, and common weeds in Australia (Thompson et al. 2011, 2015). Three of these species recovered from other plants in Australia-D. kongii, D. masirevicii, and D. middletonii-were also isolated from internal stem tissue of wilted bitou bush or stem-tip dieback symptoms. Isolates of these species caused necrotic lesions of various lengths on inoculated wounded excised and in situ stems of bitou bush in our experiments. One isolate of D. masirevicii (57327), which caused the longest lesions, was also shown to internally colonize in situ stems up to $8 \mathrm{~cm}$ beyond the lesions, although no external symptoms such as wilting of leaves developed on plants. Isolates of $D$. kongii and D. masirevicii recovered from other plant species have been shown to cause small necrotic lesions, including, in some instances, light stem streaking and leaf wilting, on stems of sunflower or peanut following wound inoculation (Thompson et al. 2011, 2018). In contrast, our study is the first, to our knowledge, to demonstrate the pathogenicity of the recently described species $D$. middletonii (Thompson et al. 2015). It is probable that D. kongii and D. masirevicii isolated from bitou bush are also pathogenic on crop plants, thus making bitou bush an alternative host for these pathogens that can facilitate their survival between cropping phases.

D. masirevicii was the only fungus isolated from bitou bush that sporulated abundantly on artificial media and, thus, could be used to inoculate bitou bush with a conidial suspension. Because $D$. masirevicii and other Diaporthe spp. had been recovered from stem-tip dieback lesions, we specifically inoculated flower clusters and stem tips because these were possible entry points into plants. A few small lesions developed on peduncles and flowers dried up prematurely in inoculated plants but no stem-tip lesions were

TABLE 2

Recovery of Diaporthe sp. colonies from in situ stem pieces of bitou bush (Chrysanthemoides monilifera subsp. rotundata) plants at approximately 5 and 10 weeks after inoculation with different Diaporthe spp. or isolates ${ }^{\mathrm{a}}$

\begin{tabular}{|c|c|c|c|c|c|}
\hline \multirow[b]{3}{*}{ Name, accession number ${ }^{b}$} & \multirow[b]{3}{*}{$\operatorname{Rep}^{c}$} & \multicolumn{4}{|c|}{ Maximum distance $(\mathrm{cm})^{\mathrm{d}}$} \\
\hline & & \multicolumn{2}{|c|}{ In situ stems experiment ${ }^{\mathrm{e}}$} & \multicolumn{2}{|c|}{ In situ flowers experiment ${ }^{f}$} \\
\hline & & Trial 1 & Trial 2 & Trial 1 & Trial 2 \\
\hline \multirow{2}{*}{ Diaporthe kongii BRIP 57332} & 2 & $\mathrm{n} / \mathrm{a}$ & $x$ & - & - \\
\hline & 3 & 1 & $x$ & - & - \\
\hline \multirow[t]{5}{*}{ D. masirevicii BRIP 57327} & 1 & 1 & 1 & $x$ & $x$ \\
\hline & 2 & 6 & 1 & 12 & 10 \\
\hline & 3 & 1 & 1 & 16 & $x$ \\
\hline & 4 & 8 & - & 4 & 14 \\
\hline & 5 & - & - & 14 & 10 \\
\hline \multirow{4}{*}{ D. masirevicii BRIP 57338} & 3 & $x$ & $x$ & 16 & $x$ \\
\hline & 4 & $x$ & - & $x$ & $\times$ \\
\hline & 5 & - & - & 12 & $x$ \\
\hline & 6 & - & - & 2 & 10 \\
\hline \multirow[t]{4}{*}{ D. middletonii BRIP 57329} & 1 & $x$ & $x$ & - & - \\
\hline & 2 & $\times$ & $x$ & - & - \\
\hline & 3 & $x$ & $x$ & - & - \\
\hline & 4 & $x$ & - & - & - \\
\hline
\end{tabular}

a Plants were inoculated by (i) placing an agar disc colonized by the fungus into an artificial wound on the main stem of a plant (in situ stems experiment) or (ii) by spraying a flower cluster on the tip of a branch with a conidial suspension of the fungus (in situ flowers experiment). No Diaporthe sp. colonies grew from the stem pieces of any of the control plants in both experiments.

${ }^{\mathrm{b}}$ Name of Diaporthe spp. followed by accession number from the Plant Pathology Herbarium (HERB-BRIP) of the Queensland Department of Agriculture, Fisheries and Forestry, Brisbane, Australia.

c Plant replicate.

${ }^{d}$ Maximum distance on the stem or branch from the inoculated wound or lesion edge or base of the flower cluster where Diaporthe sp. colonies grew from internal tissue. Symbols: - indicates fungal isolate or replicate was not included in the trial, n/a = recovery not attempted for this replicate in this trial, and $x$ indicates fungal isolate not recovered from any of the stem pieces.

${ }^{\text {e }}$ Recovery of isolates was attempted from every $1-\mathrm{cm}$ piece cut from the $8-\mathrm{cm}$ section of stem upward from the upper edge of the inoculated wounded area or the lesion that developed, if applicable, at 35 to 40 days after inoculation.

${ }^{f}$ Recovery of isolates was attempted from every $2-\mathrm{cm}$ piece of the $16-\mathrm{cm}$ section of stem downward from the inoculated cluster of flowers at 10 weeks after inoculation. 
observed within the timeframe of the experiment. Nonetheless, the fungus was confirmed to have colonized stems endophytically without causing any visible disease symptoms. D. vaccinii, which causes twig blight of blueberry, is reported to infect plants via flower buds or fully opened flowers (Daykin and Milholland 1990). The mechanisms enabling $D$. masirevicii to enter plants via flowers and grow within stems of bitou bush without being arrested by the plant likely involve modulation of the plant's immune system (Brader et al. 2017). Latent infection by pathogenic Diaporthe spp. is reported in a range of plant species in different countries and may last for several months until plants reach maturity; for example, in lupins (Shankar et al. 1998) and soybean (Sinclair 1991). More extensive disease symptoms on bitou bush such as wilting and stem-tip dieback, which are precursors to SDS, may have eventuated in our in situ experiments if they had been extended for many months. It is also possible that more than one fungus working in tandem is required for SDS to occur and, thus, further experiments should consider coinoculation of bitou bush with several of the recovered Diaporthe isolates or species in this study.

Diseased bitou bush found among dead plants at the sites where wilting was not observed were stunted and partially defoliated and had stem-tip dieback symptoms, suggesting that they had been affected to some extent by the causal agents of SDS but had, thus far, survived. The endophytic fungal communities in these diseased plants were dominated by different OTUs than Diaporthe spp. The dominant Coprinellus sp. OTU (G62A) in diseased bitou bush at sites 3 and 4 was most likely a secondary colonizer that had displaced the primary causal agents in those severely diseased plants. As well as growing in dung and soil with high organic matters, fungi in the genus Coprinellus are known to colonize woody materials, especially in late degradation stages (Oliver et al. 2010). The other dominant OTU was A. osteospermi, a ubiquitous fungus on bitou bush previously recorded from a wide range of sites across NSW (Morin et al. 2010). It has been shown experimentally to cause small necrotic leaf and stem lesions on bitou bush but no lesions that girdle stems or cause wilting or dieback (Morin et al. 2010). The potentially compromised defense system in diseased bitou bush at our sampled sites may have favored internal colonization of stems by this fungus.

A Penicillium sp. OTU (G14) was the most dominant fungal endophyte in healthy bitou bush at most sites. Endophytic Penicillium spp. are reported to promote plant growth and protect plants against biotic stresses or pathogens through the production of bioactive secondary metabolites (Nicoletti et al. 2014). Although it is likely that the Penicillium sp. OTU detected in healthy bitou bush is a mutualist endophyte that confers a range of benefits to plants, it could also protect them against SDS. Isolation of this endophyte from bitou bush and experiments to characterize its unique properties such as plant growth promotion, stress tolerance, and disease resistance (Potshangbam et al. 2017) are required to understand the roles it plays.

Metabarcoding allowed a deep survey of the fungal communities present in both plant material and soil samples collected in our study at a reasonable cost. Indeed, this culture-independent molecular method detected significantly more OTUs than the number of fungal endophytes isolated from diseased bitou bush. Although there was a perfect match between sequences of $A$. osteospermi and $D$. kongii isolates recovered from internal stem tissue and two of the OTUs detected by metabarcoding, no such perfect match was obtained with the single Fusarium sp. isolate and the four isolates of $D$. masirevicii. There are several possible explanations for this. Subsampling and pooling of samples for metabarcoding may account for such differences, because endophytes may not be evenly distributed within stems. Errors associated with sequencing methods (Nilsson et al. 2019) may also explain why no perfect sequence match was obtained between the D. masirevicii isolates and any of the other three Diaporthe sp. OTUs detected in relatively high abundance. It is also possible that $D$. masirevicii contains multiple copies of ITS1, as reported for D. eres (Udayanga et al. 2014). A single ITS1 allele representing all isolates of $D$. masirevicii was used in the custom-made database and, thus, it is conceivable that this fungus was present in the metabarcoding data but represented by a different ITS1 allele. The metabarcoding OTU abundance-by-sample results clearly indicated that Diaporthe spp. were likely important contributors in bitou bush SDS and, thus, guided us in focusing subsequent manipulative experiments on the isolated Diaporthe spp. By combining metabarcoding with culturing methods, we streamlined the research and were able to make considerable advances toward unraveling bitou bush SDS.

Our study provides circumstantial evidence that SDS of bitou bush is the result of a shift in the composition of its endophytic fungal community, from mutualist to pathogenic species. Although SDS of bitou bush could not be reproduced in our short manipulative experiments, results nevertheless provide clues to the possible underlying mechanisms. Beneficial endophytes such as the Penicillium sp. OTU present in healthy bitou bush may gradually be outcompeted by other endophytes with pathogenic capability such as the various Diaporthe spp. found associated with diseased plants. How these Diaporthe spp. could cause the extensive wilting observed in bitou bush before their sudden death remains to be investigated. It is possible that a certain level of internal colonization of plants by one or more Diaporthe spp., combined or not with specific external environmental factors stressing plants, could be required to trigger extensive wilting. The formation of multiple tyloses inside the plant xylem ahead of the fungal colonization front combined with plugging of phloem by masses of hyphae are suspected to contribute to the development of dieback symptoms in blueberry bush infected by D. vaccinii (Daykin and Milholland 1990). Phytotoxins, which are known to be produced by Diaporthe spp. (Chepkirui and Stadler 2017), could also possibly be involved in triggering such sudden wilting and death of bitou bush invaded by Diaporthe spp. Although SDS of bitou bush is beneficial to reduce the dominance of this invasive plant at several infested sites in NSW, it may also serve as a reservoir for Diaporthe spp. that are pathogenic on crop species such as sunflower (Thompson et al. 2015). The interplay between Diaporthe spp. on these different hosts remains a mystery that requires investigation. Considering the complex etiology of bitou bush SDS and putative wide host range of the Diaporthe spp. suspected to be involved, it is unlikely that it will be possible to manipulate the syndrome to achieve widespread biological control of bitou bush.

\section{ACKNOWLEDGMENTS}

We thank M. Smith (NSW National Parks and Wildlife Service [NPWS]) for his assistance during field sampling and continued support; M. Priest and K. Cowan (NSW Department of Primary Industries) for providing cultures of fungi previously isolated from bitou bush; S. Hoque (Commonwealth Scientific and Industrial Research Organisation [CSIRO] Agriculture \& Food) and R. Aveyard (former CSIRO employee) for technical assistance; a range of stakeholders for their support or permission to collect samples on their land, including the National Bitou Bush \& Boneseed Management Group, the Coastal Branch of NSW NPWS, the NSW Land \& Property Management Authority (formerly NSW Department of Lands), Bellinger Landcare, Bellingen Shire Council, Nambucca Shire Council, The North Coast Weeds Advisory Council, and various other 
agencies and volunteer groups involved in bitou bush management in the North Coast region of NSW; and T. Steinrucken and B. Gooden (CSIRO) for useful comments on an earlier version of this manuscript.

\section{LITERATURE CITED}

Aghighi, S., Burgess, T. I., Scott, J. K., Calver, M., and Hardy, G. E. S. 2016. Isolation and pathogenicity of Phytophthora species from declining Rubus anglocandicans. Plant Pathol. 65:451-461.

Aghighi, S., Fontanini, L., Yeoh, P. B., Hardy, G. E. S., Burgess, T. I., and Scott, J. K. 2014. A conceptual model to describe the decline of European blackberry (Rubus anglocandicans), a weed of national significance in Australia. Plant Dis. 98:580-589.

Altschul, S. F., Gish, W., Miller, W., Myers, E. W., and Lipman, D. J. 1990. Basic Local Alignment Search Tool. J. Mol. Biol. 215:403-410.

Benítez, M. S., Hersh, M. H., Vilgalys, R., and Clark, J. S. 2013. Pathogen regulation of plant diversity via effective specialization. Trends Ecol. Evol. 28:705-711.

Bever, J. D., Mangan, S. A., and Alexander, H. M. 2015. Maintenance of plant species diversity by pathogens. Annu. Rev. Ecol. Evol. Syst. 46:305-325.

Brader, G., Compant, S., Vescio, K., Mitter, B., Trognitz, F., Ma, L. J., and Sessitsch, A. 2017. Ecology and genomic insights into plant-pathogenic and plant-nonpathogenic endophytes. Annu. Rev. Phytopathol. 55:61-83.

Buée, M., Reich, M., Murat, C., Morin, E., Nilsson, R. H., Uroz, S., and Martin, F. 2009. 454 Pyrosequencing analyses of forest soils reveal an unexpectedly high fungal diversity. New Phytol. 184:449-456.

Burdon, J. J., and Laine, A.-L. 2019. Evolutionary Dynamics of PlantPathogen Interactions. Cambridge University Press, Cambridge, U.K.

Caporaso, J. G., Kuczynski, J., Stombaugh, J., Bittinger, K., Bushman, F. D., Costello, E. K., Fierer, N., Pena, A. G., Goodrich, J. K., Gordon, J. I., Huttley, G. A., Kelley, S. T., Knights, D., Koenig, J. E., Ley, R. E., Lozupone, C. A., McDonald, D., Muegge, B. D., Pirrung, M., Reeder, J., Sevinsky, J. R., Tumbaugh, P. J., Walters, W. A., Widmann, J., Yatsunenko, T., Zaneveld, J., and Knight, R. 2010. QIIME allows analysis of high-throughput community sequencing data. Nat. Methods 7:335-336.

Chepkirui, C., and Stadler, M. 2017. The genus Diaporthe: A rich source of diverse and bioactive metabolites. Mycol. Prog. 16:477-494.

Clarke, K. R., and Warwick, R. M. 1994. Change in Marine Communities: An Approach to Statistical Analysis and Interpretation. Natural Environment Research Council, London, U.K.

Cother, E. J. 2000. Pathogenicity of Sclerotinia sclerotiorum to Chrysanthemoides monilifera ssp. rotundata (Bitou bush) and selected species of the coastal flora in eastern Australia. Biol. Control 18:10-17.

Cother, E. J., Nikandrow, A., and Gilbert, R. L. 1996. Sclerotinia sclerotiorum, a potential biocontrol agent for Chrysanthemoides monilifera (bitou bush). Pages 529-530 in: Proc. IX Int. Symp. Biol. Control Weeds. V. Moran and J. Hoffmann, eds. University of Cape Town, Cape Town, South Africa.

Daykin, M. E., and Milholland, R. D. 1990. Histopathology of blueberry twig blight caused by Phomopsis vaccinii. Phytopathology 80:736-740.

Del Frari, G., Gobbi, A., Aggerbeck, M. R., Oliveira, H., Hansen, L. H., and Ferreira, R. B. 2019. Characterization of the wood mycobiome of Vitis vinifera in a vineyard affected by Esca. Spatial distribution of fungal communities and their putative relation with leaf symptoms. Front. Plant Sci. 10:910.

Dinoor, A., and Eshed, N. 1984. The role and importance of pathogens in natural plant communities. Annu. Rev. Phytopathol. 22:443-466.

Dowd, S. E., Callaway, T. R., Wolcott, R. D., Sun, Y., McKeehan, T., Hagevoort, R. G., and Edrington, T. S. 2008. Evaluation of the bacterial diversity in the feces of cattle using 16S rDNA bacterial tag-encoded FLX amplicon pyrosequencing (bTEFAP). BMC Microbiol. 8:125.

Downey, P. O., Holtkamp, R. H., Ireson, J. E., Kwong, R. M., and Swirepik, A. E. 2007. A review of the Chrysanthemoides monilifera biological control program in Australia: 1987-2005. Plant Prot. Q. 22:24-32.

Edgar, R. C. 2010. Search and clustering orders of magnitude faster than BLAST. Bioinformatics 26:2460-2461.

Edgar, R. C., Haas, B. J., Clemente, J. C., Quince, C., and Knight, R. 2011. UCHIME improves sensitivity and speed of chimera detection. Bioinformatics 27:2194-2200.
Felsenstein, J. 2005. PHYLIP (Phylogeny Inference Package) version 3.6. Distributed by the author. Department of Genome Sciences, University of Washington, Seattle, WA, U.S.A.

Flory, S. L., Alba, C., Clay, K., Holt, R. D., and Goss, E. M. 2018. Emerging pathogens can suppress invaders and promote native species recovery. Biol. Invasions 20:5-8.

Flory, S. L., and Clay, K. 2013. Pathogen accumulation and long-term dynamics of plant invasions. J. Ecol. 101:607-613.

French, K., Barrett, K. L., and Watts, E. 2019. The fickle activity of a fly and a moth: Variation in activity of two biocontrol agents of Chrysanthemoides monilifera. Biol. Invasions 21:1807-1815.

French, K., Ens, E., Gosper, C. R., Lindsay, E., Mason, T., Owers, B., and Sullivan, N. 2008. Management implications of recent research into the effect of Bitou bush invasion. Plant Prot. Q. 23:24-28.

Gardes, M., and Bruns, T. D. 1993. ITS primers with enhanced specificity for Basidiomycetes - Application to the identification of mycorrhizae and rusts. Mol. Ecol. 2:113-118.

Gómez, F. J. R., Navarro-Cerrillo, R. M., Perez-de-Luque, A., Osswald, W., Vannini, A., and Morales-Rodríguez, C. 2019. Assessment of functional and structural changes of soil fungal and oomycete communities in holm oak declined dehesas through metabarcoding analysis. Sci. Rep. 9:5315.

Guarnaccia, V., Groenewald, J. Z., Woodhall, J., Armengol, J., Cinelli, T., Eichmeier, A., Ezra, D., Fontaine, F., Gramaje, D., Gutierrez-

Aguirregabiria, A., Kaliterna, J., Kiss, L., Larignon, P., Luque, J., Mugnai, L., Naor, V., Raposo, R., Sandor, E., Vaczy, K. Z., and Crous, P. W. 2018. Diaporthe diversity and pathogenicity revealed from a broad survey of grapevine diseases in Europe. Persoonia 40:135-153.

Hansen, E. M., Reeser, P. W., and Sutton, W. 2012. Phytophthora beyond agriculture. Annu. Rev. Phytopathol. 50:359-378.

Haque, A., van Klinken, R. D., Goulter, K., and Galea, V. J. 2019. Assessing the potential of fungi isolated from dieback-affected trees as biological control agents for prickly acacia (Vachellia nilotica subsp. indica). BioControl 64:197-208.

Hardoim, P. R., van Overbeek, L. S., Berg, G., Pirttila, A. M., Compant, S., Campisano, A., Doring, M., and Sessitsch, A. 2015. The hidden world within plants: Ecological and evolutionary considerations for defining functioning of microbial endophytes. Microbiol. Mol. Biol. Rev. 79: 293-320.

Hüberli, D., Tommerup, I. C., Calver, M. C., Colquhoun, I. J., and Hardy, G. E. S. 2002. Temperature and inoculation method influence disease phenotypes and mortality of Eucalyptus marginata clonal lines inoculated with Phytophthora cinnamomi. Australas. Plant Pathol. 31:107-118.

Huse, S. M., Welch, D. M., Morrison, H. G., and Sogin, M. L. 2010. Ironing out the wrinkles in the rare biosphere through improved OTU clustering. Environ. Microbiol. 12:1889-1898.

Kõljalg, U., Larsson, K. H., Abarenkov, K., Nilsson, R. H., Alexander, I. J., Eberhardt, U., Erland, S., Hoiland, K., Kjøller, R., Larsson, E., Pennanen, T., Sen, R., Taylor, A. F. S., Tedersoo, L., Vrålstad, T., and Ursing, B. M. 2005. UNITE: A database providing web-based methods for the molecular identification of ectomycorrhizal fungi. New Phytol. 166:1063-1068.

Lau, M. K., Arnold, A. E., and Johnson, N. C. 2013. Factors influencing communities of foliar fungal endophytes in riparian woody plants. Fungal Ecol. 6:365-378.

Lim, Y. W., Kim, B. K., Kim, C., Jung, H. S., Kim, B. S., Lee, J. H., and Chun, J. 2010. Assessment of soil fungal communities using pyrosequencing. J. Microbiol. 48:284-289.

Ludwig, W., Strunk, O., Westram, R., Richter, L., Meier, H., Yadhukumar, Buchner, A., Lai, T., Steppi, S., Jobb, G., Förster, W., Brettske, I., Gerber, S., Ginhart, A. W., Gross, O., Grumann, S., Hermann, S., Jost, R., König, A., Liss, T., Lüßmann, R., May, M., Nonhoff, B., Reichel, B., Strehlow, R., Stamatakis, A., Stuckmann, N., Vilbig, A., Lenke, M., Ludwig, T., Bode, A., and Schleifer, K.-H. 2004. ARB: A software environment for sequence data. Nucleic Acids Res. 32:1363-1371.

Morales-Cruz, A., Figueroa-Balderas, R., Garcia, J. F., Tran, E., Rolshausen, P. E., Baumgartner, K., and Cantu, D. 2018. Profiling grapevine trunk pathogens in planta: A case for community-targeted DNA metabarcoding. BMC Microbiol. 18:214.

Morin, L. 2020. Progress in biological control of weeds with plant pathogens. Annu. Rev. Phytopathol. 58:201-223.

Morin, L., Shivas, R. G., Piper, M. C., and Tan, Y. P. 2010. Austropleospora osteospermi gen. et sp. nov. and its host specificity and distribution on Chrysanthemoides monilifera ssp. rotundata in Australia. Fungal Divers. 40:65-74. 
Nicoletti, R., Fiorentino, A., and Scognamiglio, M. 2014. Endophytism of Penicillium species in woody plants. Open Mycol. J. 8:1-26.

Nilsson, R. H., Anslan, S., Bahram, M., Wurzbacher, C., Baldrian, P., and Tedersoo, L. 2019. Mycobiome diversity: High-throughput sequencing and identification of fungi. Nat. Rev. Microbiol. 17:95-109.

Nilsson, R. H., Bok, G., Ryberg, M., Kristiansson, E., and Hallenberg, N. 2009. A software pipeline for processing and identification of fungal ITS sequences. Source Code Biol. Med. 4:1.

Oliver, J. P., Perkins, J., and Jellison, J. 2010. Effect of fungal pretreatment of wood on successional decay by several inky cap mushroom species. Int. Biodeter. Biodegr. 64:646-651.

Paseka, R. E., White, L. A., Van de Waal, D. B., Strauss, A. T., Gonzalez, A. L., Everett, R. A., Peace, A., Seabloom, E. W., Frenken, T., and Borer, E. T. 2020. Disease-mediated ecosystem services: Pathogens, plants, and people. Trends Ecol. Evol. 35:731-743.

Porras-Alfaro, A., and Bayman, P. 2011. Hidden fungi, emergent properties: Endophytes and microbiomes. Annu. Rev. Phytopathol. 49:291-315.

Potshangbam, M., Devi, S. I., Sahoo, D., and Strobel, G. A. 2017. Functional characterization of endophytic fungal community associated with Oryza sativa L. and Zea mays L. Front. Microbiol. 8:325.

Quince, C., Lanzen, A., Curtis, T. P., Davenport, R. J., Hall, N., Head, I. M., Read, L. F., and Sloan, W. T. 2009. Accurate determination of microbial diversity from 454 pyrosequencing data. Nat. Methods 6:639-641.

Raghavendra, A. K. H., Bissett, A. B., Thrall, P. H., Morin, L., Steinrucken, T. V., Galea, V. J., Goulter, K. C., and van Klinken, R. D. 2017. Characterisation of above-ground endophytic and soil fungal communities associated with dieback-affected and healthy plants in five exotic invasive species. Fungal Ecol. 26:114-124.

R Core Team. 2018. A Language and Environment for Statistical Computing. R Foundation for Statistical Computing, Vienna, Austria.

Schloss, P. D., Westcott, S. L., Ryabin, T., Hall, J. R., Hartmann, M., Hollister, E. B., Lesniewski, R. A., Oakley, B. B., Parks, D. H., Robinson, C. J., Sahl, J. W., Stres, B., Thallinger, G. G., Van Horn, D. J., and Weber, C. F. 2009. Introducing mothur: Open-source, platform-independent, community-supported software for describing and comparing microbial communities. Appl. Environ. Microbiol. 75:7537-7541.

Shankar, M., Cowling, W. A., and Sweetingham, M. W. 1998. Histological observations of latent infection and tissue colonization by Diaporthe toxica in resistant and susceptible narrow-leafed lupins. Can. J. Bot. 76:1305-1316.

Sinclair, J. B. 1991. Latent infection of soybean plants and seeds by fungi. Plant Dis. 75:220-224.

Stefani, F. O. P., Bell, T. H., Marchand, C., de la Providencia, I. E., El Yassimi, A., St-Arnaud, M., and Hijri, M. 2015. Culture-dependent and -independent methods capture different microbial community fractions in hydrocarbon-contaminated soils. PLoS One 10:e0128272.

Steinrucken, T. V., Aghighi, S., Hardy, G. E. S., Bissett, A., Powell, J. R., and van Klinken, R. D. 2017a. First report of oomycetes associated with the invasive tree Parkinsonia aculeata (Family: Fabaceae). Australas. Plant Pathol. 46:313-321.

Steinrucken, T. V., Bissett, A., Powell, J. R., Raghavendra, A. K. H., and van Klinken, R. D. 2016. Endophyte community composition is associated with dieback occurrence in an invasive tree. Plant Soil 405:311-323.

Steinrucken, T. V., Raghavendra, A. K. H., Powell, J. R., Bissett, A., and Van Klinken, R. D. 2017b. Triggering dieback in an invasive plant:
Endophyte diversity and pathogenicity. Australas. Plant Pathol. 46: 157-170.

Taylor, K., Barber, P. A., Hardy, G. E. St J., and Burgess, T. I. 2009. Botryosphaeriaceae from tuart (Eucalyptus gomphocephala) woodland, including descriptions of four new species. Mycol. Res. 113:337-353.

Thomas, J., and Leys, A. 2002. Strategic management of bitou bush (Chrysanthemoides monilifera ssp. rotundata (L.) T. Norl.). Pages 586590 in: Proc. 13th Aust. Weeds Conf. H. Spafford Jacob, J. Dodd, and J. H. Moore, eds. Plant Protection Society of Western Australia, Perth, Australia.

Thompson, S. M., Grams, R. A., Neate, S. M., Shivas, R. G., Ryley, M. J., Tan, Y. P., Aitken, E. A. B., Wright, G. C., and O'Connor, D. J. 2018. First reports of Diaporthe kongii, D. masirevicii, and D. ueckerae associated with stem and peg dieback on peanut in Australia. Plant Dis. 102:1459.

Thompson, S. M., Tan, Y. P., Shivas, R. G., Neate, S. M., Morin, L., Bissett, A., and Aitken, E. A. B. 2015. Green and brown bridges between weeds and crops reveal novel Diaporthe species in Australia. Persoonia 35: 39-49.

Thompson, S. M., Tan, Y. P., Young, A. J., Neate, S. M., Aitken, E. A. B., and Shivas, R. G. 2011. Stem cankers on sunflower (Helianthus annuus) in Australia reveal a complex of pathogenic Diaporthe (Phomopsis) species. Persoonia 27:80-89.

Udayanga, D., Castlebury, L. A., Rossman, A. Y., Chukeatirote, E., and Hyde, K. D. 2014. Insights into the genus Diaporthe: Phylogenetic species delimitation in the D. eres species complex. Fungal Divers. 67: 203-229.

van Rensburg, J. C. J., Lamprecht, S. C., Groenewald, J. Z., Castlebury, L. A., and Crous, P. W. 2006. Characterisation of Phomopsis spp. associated with die-back of rooibos (Aspalathus linearis) in South Africa. Stud. Mycol. 55:65-74.

Vranjic, J. A., Morin, L., Reid, A. M., and Groves, R. H. 2012. Integrating revegetation with management methods to rehabilitate coastal vegetation invaded by Bitou bush (Chrysanthemoides monilifera ssp. rotundata) in Australia. Austral Ecol. 37:78-89.

Wilson, C. G., and Pitkethley, R. N. 1992. Botryodiplodia dieback of Mimosa pigra, a noxious weed in Northern Australia. Plant Pathol. 41: 777-779.

Winkler, M. A., Cherry, H., and Downey, P. O., eds. 2008. Bitou Bush Management Manual: Current Management and Control Options for Bitou Bush (Chrysanthemoides monilifera ssp. rotundata) in Australia. Department of Environment and Climate Change, Sydney, NSW, Australia.

Wolfe, E. R., and Ballhorn, D. J. 2020. Do foliar endophytes matter in litter decomposition? Microorganisms 8:446.

Wood, A. R. 2006. Preliminary host specificity testing of Endophyllum osteospermi (Uredinales, Pucciniaceae), a biological control agent against Chrysanthemoides monilifera ssp. monilifera. Biocontrol Sci. Technol. 16: 495-507.

Yao, H., Sun, X., He, C., Maitra, P., Li, X. C., and Guo, L. D. 2019. Phyllosphere epiphytic and endophytic fungal community and network structures differ in a tropical mangrove ecosystem. Microbiome 7:57. 